\title{
Association between the serotonin transporter polymorphism (5HTLPR) and subjective happiness level in Japanese adults
}

Masahiro Matsunaga ${ }^{1 *}$, Tokiko Isowa $^{2}$, Kaori Yamakawa $^{3}$ and Hideki Ohira ${ }^{3}$

\author{
* Correspondence: \\ matsunag@aichi-med-u.ac.jp \\ ${ }^{1}$ Department of Health and \\ Psychosocial Medicine, Aichi \\ Medical University School of \\ Medicine, Nagakute, Aichi, 480-1195, \\ Japan \\ Full list of author information is \\ available at the end of the article
}

\begin{abstract}
Background: An epidemiological study in the USA recently reported that variations in the serotonin transporter gene-linked polymorphic region (5HTTLPR) can influence subjective well-being or happiness; specifically, individuals with long polymorphisms (L-allele carriers), associated with increased serotonin reuptake activity, reported significantly higher levels of life satisfaction compared to individuals with short polymorphisms (S-allele carriers). It is empirically known that an international discrepancy in subjective well-being exists, which may be linked to findings that the genotype distribution is different in the USA and Japan. Thus, we investigated the association between 5HTTLPR and happiness in Japan to examine whether geographical heterogeneity of well-being could be partly explained by variations in 5 HTTLPR.
\end{abstract}

Findings: Ninety-two healthy Japanese individuals were recruited (34 males and 58 females; age range, 19-40 years). Subjective happiness was evaluated using the Japanese version of the Subjective Happiness Scale. Regression analysis examining the association between $5 H T T L P R$ and subjective happiness level revealed that L-allele carriers report a significantly higher level of subjective happiness.

Conclusions: In concurrence with the epidemiological findings of the USA, this study indicates that 5HTTLPR is associated with subjective happiness levels in Japanese adults. In turn, this might provide some insight into the potential mechanism underlying international differences in subjective well-being or happiness.

Keywords: Subjective happiness level; 5HTTLPR; Population genetics; Serotonin transporter

\section{Findings}

Happiness is one of the most fundamental human goals, which has led researchers to question the source of individual happiness. Interestingly, an epidemiological study in the USA recently reported that individual heterogeneity in subjective well-being or happiness might be partly explained by variations in the serotonin transporter gene-linked polymorphic region (5HTTLPR) (De Neve, 2011), which are known to impact the expression and function of serotonin transporters (5HTT) (Hariri et al. 2002; Heinz et al. 2005). Specifically, it was found that 
individuals with long polymorphisms (L-allele carriers), associated with increased serotonin (5HT) reuptake activity, report significantly higher levels of life satisfaction compared to individuals with short polymorphisms (S-allele carriers) (De Neve, 2011). Although the follow-up work conducted by the same author and colleagues failed to replicate the original finding (De Neve et al., 2012), the 5HTT gene may be a good candidate gene for subjective well-being or happiness. Indeed, polymorphisms might be related to affective disorders, whereby S-allele carriers are more sensitive to negative emotional stimuli and have a higher susceptibility for depression and anxiety-related disorders compared to L-allele carriers (Lesch et al. 1996; Caspi et al. 2003; Ohira et al. 2009).

It is empirically known that an international difference in subjective well-being exists (Diener et al. 1995; White, 2007); for example, South Korea and Japan report below average levels of happiness and life satisfaction compared to other countries, while the USA reports above average levels (Diener et al. 1995). Given the previous finding that the genotype distribution of 5HTTLPR is different in the USA (SS: 26\%, SL: 49\%, LL: 25\%) (Pluess et al., 2010) compared to Japan (SS: 57.8\%, SL: 37.8\%, LL: 4.4\%) (Mizuno et al., 2006), we speculated that the geographical heterogeneity of subjective well-being or happiness might be partly explained by variations in 5HTTLPR. In other words, since S-allele carriers are more prone to depression, Lallele carriers might evaluate their lives more positively. The significantly lower level of L-allele carriers in Japan compared to the USA might, in turn, explain the below average level of happiness and life satisfaction reported by the Japanese population. Thus, in this study, we attempted to elucidate the association between 5HTTLPR and happiness in Japanese adults.

Ninety-two healthy participants (34 males and 58 females; age range, 19-40 years; age mean, $23.01 \pm 0.48$ years) were recruited at the Fujita Health University, following study approval by the local Ethics Committee. All participants provided written informed consent in accordance with the Declaration of Helsinki. Body mass index (BMI), smoking status, and frequency of alcohol intake were also evaluated. Smoking status was quantified as follows: $1=$ yes and $2=$ no. Frequency of alcohol intake was quantified as follows: $1=$ everyday; $2=5-6$ days $/$ week; $3=3-4$ days $/$ week; $4=1-2$ days $/$ week; $5=$ sometimes $/$ month; and $6=$ no intake. Mean BMI was $20.83 \pm 0.25$, the mean smoking status score was $1.93 \pm$ 0.03 , and the mean score for frequency of alcohol intake was $4.85 \pm 0.11$. In this study, we evaluated each participant's subjective happiness level using the Japanese version of the Subjective Happiness Scale (JSHS). The JSHS is a 4-item scale that provides a relatively stable measure of subjective happiness. Each item is evaluated by a 7-point Likert scale and the middle point (4) represents neither unhappy nor happy. The internal consistency, test-retest reliability, convergent validity, and discriminant validity of the JSHS have previously been confirmed (Lyubomirsky and Lepper, 1999; Matsunaga et al. 2011a, b; Shimai et al. 2004). The Cronbach alpha of the JSHS was 0.82 in the original paper (Shimai et al. 2004) and it was 0.77 in the present study. Polymerase chain reactions using genomic DNA extracted from fresh or frozen blood samples were performed to genotype each participant, as described previously (Ohira et al. 2009; Matsunaga et al. 2010). Genotype distribution among the participants was as follows: SS, 65 (70.6\%); SL, 25 (27.2\%); and 
LL, 2 (2.2\%). The following regression model was employed to test for genetic associations:

$$
Y=\beta_{0}+\beta_{1} G+\beta_{2} S e+\beta_{3} A+\beta_{4} B+\beta_{5} S m+\beta_{6} F+\varepsilon
$$

In this case, "G" is a matrix of variables to control for the 5HTTLPR genotype, whereby $G=2$ if the subject's genotype is $\mathrm{LL}, \mathrm{G}=1$ if the genotype is $\mathrm{SL}$, and $\mathrm{G}=0$ if the genotype is $\mathrm{SS}$. "Se" is a matrix of variables to control for sex ( $\mathrm{Se}=1$ if the subject is male and $\mathrm{Se}=2$ if the subject is female). "A" is a matrix of variables to control for age, "B" is a matrix of variables to control for BMI, "Sm" is a matrix of variables to control for smoking habit, " $F$ " is a matrix of variables to control for frequency of alcohol intake, and " $\varepsilon$ " is an individual-specific error. Subjective happiness level was divided into four categories based on the JSHS score: 1-3.5 = unhappy (below the middle point of the JSHS score (4)); 3.75-4.25= neither (around the middle point); 4.5-5.25 = happy (around point 5); and 5.5-7 = very happy (around point 6)). The distribution of subjective happiness level in the participants was as follows: unhappy, 8 (8.7\%); neither, 20 (21.7\%); happy, 41 (44.6\%); and very happy, 23 (25.0\%). Figure 1 illustrates the 5HTTLPR genotype frequency for each happiness category. Since the proportion of LL genotype was very small in this population, we grouped the SL and LL carriers together (L-allele carriers) and compared their proportion to SS carriers for each category of happiness. In the present study, the proportion of L-allele carriers was $29.3 \%$. We speculated that $\mathrm{L}$ carriers would be evenly distributed in each category; however, we found that the proportion of L carriers rose from 12.5 to $39.1 \%$ with increasing levels of subjective happiness. In contrast, the frequency of individuals with the SS genotype was highest in the lowest subjective happiness category. Table 1 depicts

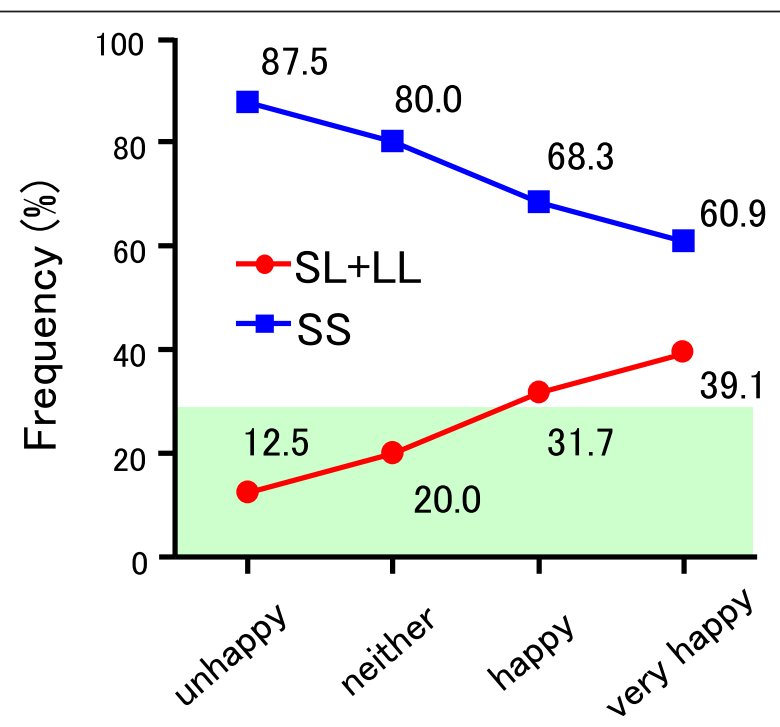

Figure 1 Percentage distribution of subjective happiness level in Japanese adults $(\mathrm{N}=92)$ and the 5 HTTLPR genotype frequency for each level of happiness category. Green zone indicates the percentage of L-allele carriers among all participants (29.3\%). 
Table 1 Results from the regression analysis examining the association between 5HTTLPR and subjective happiness level

\begin{tabular}{llll}
\hline Predictor variables & $\boldsymbol{\beta}$ & $\mathbf{t}$ & P-value \\
\hline $\mathbf{5 H T T L P R}$ long & $\mathbf{0 . 2 5 1}$ & $\mathbf{2 . 2 4 1}$ & $\mathbf{0 . 0 2 8}$ \\
\hline Sex & 0.206 & 1.798 & 0.076 \\
\hline Age & -0.036 & -0.323 & 0.747 \\
\hline BMl & -0.003 & -0.030 & 0.976 \\
\hline Smoking habit & -0.011 & 0.096 & 0.924 \\
\hline Frequency of alcohol intake & -0.039 & -0.314 & 0.755 \\
\hline $\mathrm{N}$ & 92 & & \\
\hline Adjusted $R^{2}$ & 0.038 & & \\
\hline $\begin{array}{l}\text { All predictor variables were included in the regression analysis. } \boldsymbol{\beta} \text {, Standardized beta coefficients. Bold values indicate } \\
\text { significant variables. }\end{array}$ & &
\end{tabular}

the results of the regression model, which tested the hypothesis that variations in 5HTTLPR are associated with subjective happiness. The model included variables for age, gender, BMI, smoking habit, and alcohol intake, and it demonstrates that individuals with long polymorphisms of the $5 \mathrm{HTT}$ are significantly associated with an increased level of subjective happiness $(p<0.05)$.

In concurrence with the epidemiological findings in the USA, the present study indicates that 5HTTLPR is associated with subjective happiness levels in Japanese adults, although this study is small-scale, with 92 individuals, as compared to the current standards in behavioral genetics. Given the difference regarding genotypic distribution in the USA and Japan, this finding provides some insight into the potential mechanism underlying international heterogeneity of subjective well-being or happiness. However, while the data offer a genetic explanation for subjective happiness, the underpinning association between 5HTTLPR and subjective happiness remains obscure. One speculation may be that brain functions are influenced by 5 HTTLPR.

Recent neuroimaging studies have indicated that the default mode network, which includes the medial prefrontal cortex, perigenual anterior cingulate cortex (pACC), posterior cingulate cortex, and superior temporal gyrus, is implicated in episodic memory retrieval, theory of mind, and prospection (vision of the future) (Buckner and Carroll, 2007; Nakao et al. 2012; Heine et al. 2012). Previous reports have suggested that the default mode network may be functionally important for the evaluation of subjective happiness because our assessment of subjective happiness relies heavily on our memories, future plans, and self-reflection (Berridge and Kringelbach, 2011). Interestingly, previous studies have indicated that 5HTTLPR can influence structural properties of the default mode network. For example, the gray matter volume of the pACC is significantly reduced in S-allele carriers compared to L-allele carriers (Pezawas et al. 2005). Functional and structural magnetic resonance imaging studies have demonstrated that high gray matter volume within specific brain regions is linked to elevated function (Giménez et al. 2004; Hamzei et al. 2012); thus, reduced gray matter volume in the pACC of S-allele carriers might influence their evaluation of subjective happiness. However, further studies are required to corroborate this postulation. 


\author{
Abbreviations \\ BMI: Body mass index; JSHS: Japanese version of the subjective happiness scale; pACC: Perigenual anterior \\ cingulated cortex; 5HT: Serotonin; 5HTT: Serotonin transporter; 5HTTLPR: Serotonin transporter gene-linked \\ polymorphic region.
}

\title{
Competing interests
}

The authors declare that they have no competing interests.

\section{Authors' contributions}

Conceived and designed the experiments: MM. Performed the experiments: MM, TI, KY. Analyzed the data: MM. Wrote the paper: MM, HO. Helped with the experimental design and data analysis: TI, KY, HO. All authors read and approved the final manuscript.

\section{Acknowledgements}

This study was supported by a Grant-in-Aid for Scientific Research from the Japan Society for the Promotion of Science (25750354 to MM). The funders had no role in study design, data collection, analysis, decision to publish, or preparation of the manuscript.

\section{Author details}

${ }^{1}$ Department of Health and Psychosocial Medicine, Aichi Medical University School of Medicine, Nagakute, Aichi, 480-1195, Japan. Department of Gerontological Nursing, Mie University School of Nursing, Tsu, Mie, 514-8507, Japan ${ }^{3}$ Department of Psychology, Nagoya University Graduate School of Environmental Studies, Nagoya, Aichi, 464-8601, Japan.

Received: 12 August 2013 Accepted: 1 October 2013

Published: 12 Nov 2013

\section{References}

Berridge, KC, \& Kringelbach, ML. (2011). Building a neuroscience of pleasure and well-being. Psychology of Well Being, 1(1), 1-3.

Buckner, RL, \& Carroll, DC. (2007). Self-projection and the brain. Trends Cogn Sci, 11(2), 49-57.

Caspi, A, Sugden, K, Moffitt, T, Taylor, A, Craig, I, Harrington, H, McClay, J, Mill, J, Martin, J, Braithwaite, A, \& Poulton, R. (2003). Influence of life stress on depression: moderation by a polymorphism in the 5-HTT gene. Science, 301, 386-389.

De Neve, JE. (2011). Functional polymorphism (5-HTTLPR) in the serotonin transporter gene is associated with subjective well-being: evidence from a US nationally representative sample. J Hum Genet, 56, 456-459.

De Neve, JE, Christakis, NA, Fowler, JH, \& Frey, BS. (2012). Genes, economics, and happiness. Journal of Neuroscience, Psychology, and Economics, 5, 193-211.

Diener, ED, Suh, EM, Smith, H, \& Shao, L. (1995). National differences in reported subjective well-being: why do they occur? Soc Indic Res, 34, 7-32.

Giménez, M, Junqué, C, Narberhaus, A, Caldú, X, Salgado-Pineda, P, Bargalló, N, Segarra, D, \& Botet, F. (2004). Hippocampal gray matter reduction associates with memory deficits in adolescents with history of prematurity. Neuroimage, 23(3), 869-877.

Hamzei, F, Glauche, V, Schwarzwald, R, \& May, A. (2012). Dynamic gray matter changes within cortex and striatum after short motor skill training are associated with their increased functional interaction. Neuroimage, 59(4), 3364-3372.

Hariri, AR, Mattay, VS, Tessitore, A, Kolachana, B, Fera, F, Goldman, D, Egan, MF, \& Weinberger, DR. (2002). Serotonin transporter genetic variation and the response of the human amygdala. Science, 297(5580), 400-403.

Heine, L, Soddu, A, Gómez, F, Vanhaudenhuyse, A, Tshibanda, L, Thonnard, M, Charland-Verville, V, Kirsch, M, Laureys, S, \& Demertzi, A. (2012). Resting state networks and consciousness: alterations of multiple resting state network connectivity in physiological, pharmacological, and pathological consciousness States. Front Psychol, 3, 295.

Heinz, A, Braus, DF, Smolka, MN, Wrase, J, Puls, I, Hermann, D, Klein, S, Grüsser, SM, Flor, H, Schumann, G, Mann, K, \& Büchel, C. (2005). Amygdala-prefrontal coupling depends on a genetic variation of the serotonin transporter. Nat Neurosci, 8, 20-21.

Lesch, KP, Bengel, D, Heils, A, Sabol, SZ, Greenberg, BD, Petri, S, Benjamin, J, Müller, CR, Hamer, DH, \& Murphy, DL. (1996). Association of anxiety-related traits with a polymorphism in the serotonin transporter gene regulatory region. Science, 274(5292), 1527-1531.

Lyubomirsky, S, \& Lepper, HS. (1999). A measure of subjective happiness: preliminary reliability and construct validation. Soc Indic Res, 46(2), 137-155.

Matsunaga, M, Murakami, H, Yamakawa, K, Isowa, T, Kasugai, K, Yoneda, M, Kaneko, H, Fukuyama, S, Shinoda, J, Yamada, J, \& Ohira, H. (2010). Genetic variations in the serotonin transporter gene-linked polymorphic region influence attraction for a favorite person and the associated interactions between the central nervous and immune systems. Neurosci Lett, 468(3), 211-215.

Matsunaga, M, Isowa, T, Yamakawa, K, Tsuboi, H, Kawanishi, Y, Kaneko, H, Kasugai, K, Yoneda, M, \& Ohira, H. (2011a). Association between perceived happiness levels and peripheral circulating pro-inflammatory cytokine levels in middle-aged adults in Japan. Neuroendocrinol Lett, 32(4), 458-463.

Matsunaga, M, Murakami, H, Yamakawa, K, Isowa, T, Fukuyama, S, Shinoda, J, Yamada, J, \& Ohira, H. (201 1b). Perceived happiness level influences evocation of positive emotions. Nat Sci, 3(8), 723-727.

Mizuno, T, Aoki, M, Shimada, Y, Inoue, M, Nakaya, K, Takahashi, T, Itoyama, Y, Kanazawa, M, Utsumi, A, Endo, Y, Nomura, T, Hiratsuka, M, Mizugaki, M, Goto, J, Hongo, M, \& Fukudo, S. (2006). Gender difference in association between polymorphism of serotonin transporter gene regulatory region and anxiety. J Psychosom Res, 60(1), 91-97. 
Nakao, T, Ohira, H, \& Northoff, G. (2012). Distinction between externally vs. internally guided decision-making: operational differences, meta-analytical comparisons and their theoretical implications. Front Neurosci, 6, 31.

Ohira, H, Matsunaga, M, Isowa, T, Nomura, M, Ichikawa, N, Kimura, K, Kanayama, N, Murakami, H, Osumi, T, Konagaya, T, Nogimori, T, Fukuyama, S, Shinoda, J, \& Yamada, J. (2009). Polymorphism of the serotonin transporter gene modulates brain and physiological responses to acute stress in Japanese men. Stress, 12(6), 533-543.

Pezawas, L, Meyer-Lindenberg, A, Drabant, EM, Verchinski, BA, Munoz, KE, Kolachana, BS, Egan, MF, Mattay, VS, Hariri, AR, \& Weinberger, DR. (2005). 5-HTTLPR polymorphism impacts human cingulate-amygdala interactions: a genetic susceptibility mechanism for depression. Nat Neurosci, 8(6), 828-834.

Pluess, M, Belsky, J, Way, BM, \& Taylor, SE. (2010). 5-HTTLPR moderates effects of current life events on neuroticism: differential susceptibility to environmental influences. Prog Neuro-Psychopharmacol Biol Psychiatry, 34, 1070-1074.

Shimai, S, Otake, K, Utsuki, N, Ikemi, A, \& Lyubomirsky, S. (2004). Development of a Japanese version of the subjective happiness scale (SHS), and examination of its validity and reliability. Japanese Journal of Public Health, 51, 845-853.

White, A. (2007). A global projection of subjective well-being: a challenge to positive psychology? Psychtalk, 56, 19-20.

10.1186/2211-1522-3-5

Cite this article as: Matsunaga et al: Association between the serotonin transporter polymorphism (5HTLPR) and subjective happiness level in Japanese adults. Psychology of Well-Being: Theory, Research and Practice 2013, 3:5

Submit your manuscript to a SpringerOpen ${ }^{\circ}$ journal and benefit from:

- Convenient online submission

- Rigorous peer review

- Immediate publication on acceptance

- Open access: articles freely available online

- High visibility within the field

- Retaining the copyright to your article

Submit your next manuscript at $\gg$ springeropen.com 